Pakistan Journal of Education

Vol.37, No.1, 2020, 1-20

\title{
Assessing ODL Teachers/Tutors' Opinion about Inclusion of Children with Emotional, Social and Behavioural Difficulties in ODL
}

\author{
Zahid Majeed ${ }^{*}$
}

\begin{abstract}
In Pakistan about $2.49 \%$ of population is with special needs including hearing, visual impairment, mentally challenged, physically handicapped and multiple handicaps. Only $1 \%$ of this population has access to education and higher education is almost not in access. Formal universities have no capacity, arrangements and skills to include the students with special needs. Open and Distance Learning is most suitable and accommodative mode for them so much of them are getting education through ODL mode. The study aim was to determine the etutors arrogances to include students having emotional, social and behavioural difficulties (ESBD) seeing the impact of physical age, knowhow, academic education/degrees and the help they had from AIOU. Additional it was explored the connection between willingness and attitudes to be with ESBD students at ODL classroom/system where as exploring the obstacles in effective inclusion of ESBD. Researcher selected 200 e-tutors/e-instructors as sample for the study and most of them from Islamabad region. The study was mixed design i.e. quantitative and qualitative methods. Data collected in the form of numbers was by questionnaire of two scales and the qualitative through open ended questions. Correlation was used to discover the relationship between physical age, professional practices (experiences), academic education and help they had with arrogances and readiness. The researcher used the thematic analysis to analyse the qualitative data/information. Findings of the study directed that attitudes of e-tutors has good impact and relationship when they get help from the AIOU in the form training, assistant teachers and financial support. The study recommended that tutors should be trained to assess the special needs and characteristics of emotional, social and behavioural disordered students. Also modified teaching methods/pedagogies should be part of their pre and in-service teacher training progarmmes.
\end{abstract}

Keywords: ODL teachers/tutors, inclusion, special need students

\footnotetext{
*Assistant Professor, Department of Special Education, AIOU, Islamabad. Email: zahid_majeed@aiou.edu.pk
} 


\section{Introduction}

In Pakistan, a child is categorized or labeled as special child when the Government Medical officer stamped it as disabled as per Ordinance or law of Pakistan (1981). We can imagine how old and limited it is. Also, special need or disability is limited to only four very prominent disabilities like blind, hearing impaired/deaf, mental disorder/retardation and physically disabled. No other special need is included in the law, therefore children with learning difficulties, social, emotional and behavioural difficulties are never considered as disability or special need. Most of the time such types of special needs are counted in mental retardation. When any Government hospital certified the child as special child then he/she is eligible for additional support of education and health. Inclusion is very new concept in Pakistan so educationists and Government officials are not aware about it or mixed or confused it with special education. Different stakeholders like normal children and their parents, teachers, head of educational institutions and Government officials showed different issues on inclusion of special need students. We can imagine how much it will be challenging to take in students with Emotional, Social and Behavioural Difficulties (ESBD) as inclusion visual, hearing, mental and physically disabled children is still not in practice. There are few private and Government institutions voluntarily or through different projects practicing inclusion. In this situation we can imagine inclusion of children with ESBD can be a big challenge for mainstream schools and universities settings because of children multifaceted and individual range of special needs characteristics with some more disorders of development, like disorder of language and Attention Deficit Hyperactivity Disorder (ADHD) (Cole \& Visser, 2005). Ofsted in 2005 published a reported that accommodating ESBD in mainstream system of education is much challenging and teachers are lacking with effective strategies to support such students (Evans, Harden, $\&$ Thomas, 2004). Armstrong (2013) concluded that teachers of formal schools, colleges and universities can handle or accommodate ESBD if they have training, commitments, willingness and attitudes towards inclusion. Teachers' perception on inclusion of ESBD reported much positive in developed countries and negative in under developed countries (Broomhead, 2013) like in Pakistan. Hastings, R. P., \& Oakford, S. (2003) reported positive opinion and perceptions of parents and teachers for the inclusion of special need children and ESBD. Many studies in Pakistan on inclusion of special need children concluded that teachers of mainstream educational institutions including universities are reluctant (Hameed, 2014). 
Monsend Ewing \& Kwoka (2014) suggested that perceptions of mainstream teachers on inclusion of ESBD influenced by the way they administer their normal classroom environment and how they understood and interpret the support needed and available to them and for the ESBD children. They also recommended inclusion of ESBD depends upon teachers' attitudes and willingness and their perception of adequate support and classroom environment. Teachers with more responsible attitudes appeared to be more willing to accommodate ESBD in their mainstream classroom (Ryan, 2009). Hwang\& Evans (2011) found a clear division on inclusion of ESBD in mainstream education. In addition to that nature and range of their special needs, available time and support were other key factors to include or not. Same findings were drawn by McGregor \& Campbell (2001); attitudes of Scotland teachers to include the children with autism. Inclusion of ESBD also varies in teachers teaching at primary and secondary level. Primary teachers' attitudes and getting training to implement inclusion is more positive as compare to secondary school teaches (Cook, Cameron, \& Tankersley, 2007). They also concluded that teachers spent more time with ESBD increased the attitudes, familiarities, improve their knowledge and relationship with ESBD children. Faculty members of universities teachers showed their concerns that achievements of ESBD students will be less if we included in mainstream classroom (Foorline \& Keene, 2008). In Australia, Gerber (1988) suggested that teachers are reluctant to included students with ESBD because they think or felt they will do much effort to accommodate or address their special needs. Teachers also showed their challenges and limitations of abilities and attentiveness of particular requirements to develop environment which is more inclusive. They reported that they are unaware or lacking the skills awareness and teaching strategies.

Jordan, Schwartz, \& McGhie-Richmond (2009) reported ESBD or special need children concerns of unskilled teachers and their awareness level also hindered the inclusion policies. Level of teachers' awareness and training to handle ESBD in mainstream classroom also effects significantly their perspectives, practices and ability to make adaptations, also training supports increased their level of acceptance and willingness (Hwang \& Evans, 2011). Yan \& Sin (2014) concluded that inclusion of ESBD depends upon teachers' perception of adequate support they received and classroom environment they have.

Researches on inclusion suggested that factors other than academic support and classroom environment also affect the teachers' attitudes and perception of ESBD achievements with all the support and skilled manpower (Hwang \& Evans, 2011). In summary researchers suggested 
that number of teachers felt they are lacking the skills to create an inclusion environment in their classrooms to accommodate ESBD students. Also good training can enhance the ESBD children level of achievements. Access to all types of resources, included technology can also enhance the learning environment of ESBD children (Hager \& Hodkinson, 2009). Many teachers at formal universities and ODL institutions argued that ESBD students are the most challenging and least desired in an inclusive classroom. They also reported the reason of pressure on teachers because of their behavioral and emotional problems (Avramidis, Bayliss, \& Burden, 2000). According to a survey conducted by Scanlon \& Barnes(2013) mainstream school teachers' willingness and feelings to include students with ESBD is not encouraging, they felt most of them are not prepared to meet the demanding behaviour by the ESBD. Most of them suggested supporting teachers can help them in inclusion of ESBD and their skills are also not allowing them to include ESBD (Humphrey, \& Symes, 2018). Perception of ODL tutors or instructors on social, moral support and experience of bullying behaviour is also not positive. Teacher's own belief helps in more adaptations and innovative intervention techniques to manage the demands of ESBD (Scanlon \& Barnes, 2019).

In conclusion tutors/teachers of higher education as well as school education are with limited feelings and enthusiasm to include the students having ESBD (qualitative and quantitative researches). In Pakistan very few examples and good practices of inclusion and researches concluded teachers are not willing and with divided opinion to include the ESBD at higher education. Only AIOU (ODL system $/ /$ mode) including children with special needs, every year more than 500 students get admission in under and post graduate level. In 2018-2019 a pilot study was conducted to include the ESBD children at master level programs. In the study major aim to check the ODL tutors' opinions and perceptions on inclusion of ESBD. Also, it was checked whether tutor's age, experience, academic and professional qualifications and different types of support they received, influenced their attitudes to include children with ESBD in ODL system of education. Also determined the connection between tutors' attitudes and willingness to teach students with ESBD. Barriers to success of inclusion were also investigated. Literature review and researches on inclusion of ESBD concluded younger tutors/instructors are with more positive attitudes towards inclusion and greater willingness to include them. In the current research it was hypothesized that recovering different types of support like academic, social, financial, human and technical there will be more willingness to include ESBD children (Glazzard, 2018). 


\section{Objectives of the Study}

Study objectives were:

1. To find out the demographic variables support inclusion of Emotional, social and behavioral difficulties students in ODL system.

2. To explore the technical, human, social, professional and financial support received by the tutors from the AIOU in implementing the inclusion policy.

3. To explore the barriers towards inclusion and tutor's willingness towards inclusion of ESBD in ODL.

4. To recommend policy implementation strategies for ODL and formal system of higher education.

\section{Research Methodology/Procedure}

The study was on mixed research approach/design by using quantitative and qualitative methods. The researcher used two instruments i.e. questionnaire and semi-structured interviews. For the analysis correlation was used to look at the association between the physical age, teaching time they spent in school, academic education/degrees and academic/financial/ technical help they had from the administration of open and distance learning. Researcher used thematic analysis for the analysis of qualitative data. Two scaled questionnaires were developed and pilot tested because of the perspectives of language and comprehension.

\section{Population and Sample}

Part time tutors or instructors attached with Allama Iqbal Open University were the population of the study. Most of them were tutors of Bachelor and Master level programs, therefore they were experienced and oriented with the open and distance learning system Also they were with the background of special education either having academic qualification of MA/MEd Special Education or teaching experience of special need students. The sample of the study was 100 tutors (50 male and 50 females), all were selected on voluntarily basis. The researcher floated the request with aim of the study and received consent of 210 participants. Only MA/MEd Special Education tutors/instructors were selected for the study. The age range of the selected tutors was 25-50 years. Teaching experience of the participants was between 5 years to 25 years in open and distance learning i.e. with Allama Iqbal Open University, Pakistan. Academic qualifications of the participants were 
Master in Special Education with additional qualifications of Professional Degrees in Teacher Education, Psychology, Sociology, Social Work, Physical Education and Educational Planning and Management. A three days introductory and orientation training was arranged for the participants of the study. They also have experience to teach emotional, social and behavioral disturbed students in formal and ODL system of education. Researcher officially approached the participants through Directorate of Regional Services, AIOU and parent departments of participants i.e. head teacher of their schools. Questionnaire and semi-structured interviews first pilot tested on small group (10) of ODL tutors. It was realized few questions and interview questions need revision or rephrasing. After pilot test both instruments were applied personally by the researcher. The reason of personally administer the instruments was the comprehensive knowledge on emotional, social and behavioral concepts in the context of Pakistani culture and ODL system. The same was instructed or briefed to the participants during three days training. All the 100 participants responded filled in the questionnaire and 20 participants (10 male and 10 female) participated in interviews. A certificate of research participation was issued to all the participants.

\section{Tutors Academic Qualifications and Support from ODL Administration}

Researcher adopted scaled produced by Kristie, Rebecca \& Andrew (2018) to collect the information or data on teachers' qualifications. The scale was slightly changed as it was adopted for the tutors of open and distance learning. Respondents were asked to highlight their highest professional degree i.e. special education and highest academic qualification (other than special education). Their other qualifications like psychology, sociology, social work, teacher education and educational planning and management were also scored with special education. Tutor skills in their profession scored by the researcher from high i.e. six and lowest one and an additional qualification point was also given for each academic qualifications. Total scores therefore ranged from the highest score of 6 to lowest score of 1 and additional points were given if needed. Professional qualifications began from BS/BEd Four Years Program up to Doctoral level and same for academic qualifications.

As Kristie (2018) used a similar scale for the collection of data on the support received, researcher used almost the same scale with some changes that information collected from the participants on academic, 
financial, human, moral and technical support received they received from the Open and Distance Learning administration. The support they received was specified by them by ticking optional boxes on different types of support they received. The scoring was made by one point for each support. Highest score or point was 5 , which mean they have full support and the lowest point or score was 0 , which mean no support.

\section{MATIES: Multidimensional Attitudes Toward Inclusive Education Scale}

To check or calculate the e-tutors' feelings of general inclusion of special education needs or disabled or disabilities researcher used MATIES (Kristie, 2018). Actually, Kristie team used customized edition of this scale developed by MacFarlane \& Woolfson in 2013. To measure the attitudes of ODL tutors towards inclusion of emotional, social and behavioral difficulties students in Open and Distance Learning same scale or tool was used. The scale was consisted of eighteen items/questions, out of which nine were positive in nature and nine were negative in nature. For example, one of the positive item was, 'as a teacher ready to motivate the children with ESBD to take part or attend the activities social in nature in my mainstream classroom. On the other hand negative item, 'As a teacher of inclusive classroom most of the time irritated to arrange or have academic help or facilitate personal needs of ESBD students'. e-Tutor answered or replied every item by using Likert Scale of one to nine points that how much he/she is with the item or against. Analysis showed maximum score of e-tutor towards inclusion was one hundred and sixty-two and if he/she is disagreed then the lowest was just eighteen In the study Cronbach's alpha for the revised scale (revised in context of Pakistani culture and system of education) was .71 (MacFarlane \& Woolfson, 2013).

\section{Tutors Willingness to teach Students with Severe Disabilities Scale}

A modified scale (adapted by MacFarlane \& Woolfson, 2013) was used to measure the tutors' willingness on inclusion of students with severe disabilities and Special Education Needs into Open and Distance Learning. Actually, scale was originally developed or created by Rakap and Kaczmarek (2010) while studying teachers' attitudes towards inclusion in Turkey. As mentioned by Kristie (2018) in the research conducted on Social, Emotional and Behavior Difficulties (SEBD) by using a modified version of the scale included or concentrating on children with SEBD in mainstream schools. They further modified the 
scale by altering the scoring to match the 1 to 9 Likert scale used in the MATIES, which the tutors used to provide their opinion to a series of statements. Tutors' willingness to working with emotional, social and behavior difficulties consisted of numerous elements which include tutors agreement to have extra training on ESBD and be open to make adaptation in their ODL teaching practices. The vignette included the details about the ODL student stage of educational development, their personality and overall general behavior. In scale one of the statement on it was 'I would support the idea of including ESBD students in my ODL classroom/tutorial meeting' and 'I would accommodate and adopt the way I guide/instruct all students so they would be able to participate'. Scores range on the vignette of willingness was from 8 to 72 , and a total obtained by summing all the responses of the tutors. A low score was interpreted as less willing and a high score as more willing to accommodate student with ESBD into ODL system or environment. Cronbach's alpha for the scale showed high internal consistency at .86 (MacFarlane \& Woolfson, 2013).

\section{Qualitative Questions on Inclusion and Working with Students SEBD}

For the in-depth information and teachers' perspectives on inclusion of ESBD students in Open and Distance Learning semi-structured interviews were conducted room 20 participants $(10$ male and 10 female). The main themes of interview were the same developed or used by the Kristie (2018) derived from the literature inclusion of disabled children in mainstream classrooms (Cook et al., 2007 Cook, B. G., Cameron, D. L., \& Tankersley, M. 2007). The studied conducted by McGregor \& Campbell (2001) and McGregor. E., \& Campbell, E. (2001) on integration/inclusion of autistic children also helped the researcher to develop themes of the interview. The main aim to conduct interviews or collect qualitative data was to get information to help in richness and contextual information to the quantitative data, also help us in purposeful reflections on tutors' attitudes towards the inclusion of students with ESBD in ODL system. The main themes of interview questions were inclusion and teaching students with ESBD. The questions were:

Q.1 Implementation of Inclusive policy or create an inclusive environment for ESBD students are biggest problems for ODL tutors. In your opinion what are the problems do you faced while implementing an inclusion environment for students with ESBD?

Q.2 What academic, technical, financial, human and practical help or support do you have to accommodate students with social, 
emotional and behavioral difficulties into Open and Distance Learning system?

Q.3 As ODL tutor you earned good experience, what do you suggest or recommend to make the ODL more inclusive and more successful for the tutors and ODL students?

\section{Formal Permission and Research Ethics}

Researcher first get permission from the researcher conducted same research on children with mainstream classroom. A formal permission was also requested to Directorate of Regional Services for the data of tutors with specific qualifications. Tutors were contacted through the consent and permission of their head teachers because in AIOU they are part time tutors and they are permanent employee of the mainstream schools of Punjab. More than 300 tutors were contacted through emails, phone class, personal visits and by post. Volunteer tutors then gave their consent as participant by consent forms. Researcher followed the research and personal ethics and ensured privacy, secrecy and confidentiality of data/information collected from tutors and AIOU. In research write-up alternate names or abstract identity was ensured or used.

\section{Esults/Findings Descriptive Analysis}

\section{Table 1}

\section{Age, Experience and Qualifications}

\begin{tabular}{llllll}
\hline & $N$ & Mean & SD & Range & Skew \\
\hline Physical Age (years) & 100 & $25-50$ & 2.21 & $25-50$ & .596 \\
Professional Experience in ODL & 100 & 8.94 & 9.68 & $5-25$ & 1.20 \\
Academic Qualifications & 100 & 3.69 & .845 & $2-6$ & 1.45 \\
Professional Qualifications & 100 & 4.59 & .951 & $0-5$ & 1.63 \\
Academic, Human, Financial, Technical, & 100 & 2.38 & 1.34 & $0-5$ & .298 \\
Moral Support Received & & & & & \\
MATIES (16-156) & 100 & 121 & 15.75 & $988-152$ & -.512 \\
TWSD (7-68) & 100 & 55.94 & 6.84 & $43-69$ &.- .416 \\
\hline
\end{tabular}

Descriptive analysis of table 1 depicts that most of the tutors are in the age range of 25-50 years and most of them are with experience more than 5 years, their academic qualifications are from Master to $\mathrm{PhD}$ level most of them are with social sciences background, all of them holding Master in Special Education but 2-3 are with M.Phil and PhD in Special Education. They hold special education as professional qualification. 
ODL Support received by the tutors ranged from less support (2) to full support (5). A very encouraging or positive score range reflecting positive attitudes and willingness to accommodate students with Emotional, Social, and Behavioral Difficulties. One of the variables that may contribute towards positive attitude and willingness is their experience of teaching students with special needs. Let's do the correlation between the variables in table 2 .

Table 2

Bivariate correlations between the predictor variables and outcome variables of TWSD and MATIES

\begin{tabular}{|c|c|c|c|c|c|c|}
\hline & Age & $\begin{array}{l}\text { Professional } \\
\text { Experience } \\
\text { in ODL }\end{array}$ & $\begin{array}{l}\text { Academic } \\
\text { Qualifications }\end{array}$ & $\begin{array}{l}\text { Professional } \\
\text { Qualifications }\end{array}$ & $\begin{array}{l}\text { Academic, } \\
\text { Human, } \\
\text { Financial, } \\
\text { Technical, } \\
\text { Moral } \\
\text { Support } \\
\text { Received } \\
\end{array}$ & MATIES \\
\hline $\begin{array}{l}\text { Professional } \\
\text { Experience in } \\
\text { ODL }\end{array}$ & $.758^{* * *}$ & & & & & \\
\hline $\begin{array}{l}\text { Academic } \\
\text { Qualifications }\end{array}$ & -.129 & -.071 & & & & \\
\hline $\begin{array}{l}\text { Professional } \\
\text { Qualifications }\end{array}$ & -.198 & -.086 & & & & \\
\hline $\begin{array}{l}\text { Academic, } \\
\text { Human, } \\
\text { Financial, } \\
\text { Technical, } \\
\text { Moral Support } \\
\text { Received }\end{array}$ & -.275 & .291 & -.095 & -.095 & & \\
\hline MATIES (16-156) & -.197 & $-.394 * *$ & .007 & .007 & $.375 * *$ & \\
\hline TWSD (7-68) & -.213 & $-.364 * *$ & .221 & .221 & $.257 * *$ & $.613 * *$ \\
\hline
\end{tabular}

Table reflects there are multidimensional attitudes of ODL tutors towards inclusive education scale and TWSD is ODL tutors' positive willingness to work with ESBD students. Table also depicts that age of the ODL tutors is strongly correlated with their professional and academic experience; however, variable age not showed other significant correlations with any other variables. Matrix of correlation also suggested that experience in the ODL tutoring significantly correlated and correlated negatively with the willingness and attitudes scale scores. We can say more the experience a tutor has the more positive and strong attitudes they have towards inclusion and willingness to work or teach students with ESBD lessen. There is no significant correlation between the number and type of qualifications (academic and professional) with any of the scales or any other variables. There is a significant correlation between technical, human, financial, professional and moral support 
received with attitudes of ODL tutors. This suggested on receiving more support by ODL tutors there will be more strong and positive attitude towards the inclusion of ESBD students in ODL system. If we conclude the analysis we can say that there is moderate to string significant correlations in MATIES and TWSD, which indicating that there was rhythm into related trends.

Researcher also performed multiple linear regression on ODL tutors' attitudes towards inclusion of students with emotional, social and behavioral difficulties in ODL system, as calculated by means of locally modified MATIES. In that the variables of predictors were physical age of the ODL tutors, their experience as ODL tutor, academic and professional qualifications and technical, human, financial, moral and professional support they received from AIOU. It was found that solution or model was significant and reasonable fit $(\mathrm{f}(3.98+=5.91, \mathrm{p}<.001$; $\mathrm{r} 2=.29 .8, \mathrm{p}<.001)$. Age $(\beta=6.38, \mathrm{t}(97)=3.01, \mathrm{p}=.05)$, experience as ODL tutor $(\beta=-1.71, \mathrm{t}(97)=-2.94, \mathrm{p}<.001)$ and all type of support the ODL tutors received from AIOU $(\beta=4.99, \mathrm{t}(97)=2.65, \mathrm{p}=.007)$ and most of them were accounted for the significant amounts of independent variance. Experience as ODL tutor in AIOU reflected a negative association with ODL attitude which means they must spent more time in ODL academic support for the ODL learners, the more positive attitudes. Also table depicts that ODL tutors academic and professional not to be a significant prophet of attitudes towards inclusion of ESBD $(\beta=1.13, \mathrm{t}(97)=.527, \mathrm{p}=.578)$.

To check or test the tutors' attitudes towards inclusion of ESBD students second multiple linear regression analysis was used which significantly predicted tutors' willingness, on controlled support they received from AIOU. The reason to do it was to check the barriers for a positive inclusion of ESBD students. It was found by Kristie that less the support received is cause of barriers towards inclusion of disabled students. Therefore, researcher found that regression results highlighted predicators explained $36.8 \%$ of variance $(\mathrm{F}(2,39)=13.95, \mathrm{p}<.001)$. Analysis also showed that attitudes of ODL tutors significantly predictors willingness $(\beta=.267, \mathrm{t}(97)=4.63, \mathrm{p}<.001)$; though, all types of support received did not $(\beta=.119, \mathrm{t}(97)=.137, \mathrm{p}=.797)$. It is suggested or recommended that the attitudes account for the variance regardless of the technical, human, financial, professional and moral support received by the ODL tutors from AIOU. 


\section{Qualitative Analysis of Semi-Structured Interviews}

Questionnaire was one of the research instruments and we have discussed its analysis in descriptive analysis. For in-depth and more detailed information on research questions was collected through semistructured interviews. Researcher developed three basic questions which were based on research questions and linked with the information collected through questionnaire (MATIES and TWSD). Thematic analysis technique was used for the analysis of data collected through three open ended questions. On each questions a clear theme was identified from the responses of participants. In result of this analysis three themes in total were i) attitudes and willingness towards inclusion, ii) types of support received from ODL system, and iii) suggestions and recommendations for the implementation of inclusion policy in ODL. The themes were based on the research questions so most of the information provided by tutors was overlapping with the information they provided through MATIES and TWSD (Questionnaires).

\section{Theme 1 - Attitude and Willingness toward Inclusion}

Twenty volunteer tutors (10 male and 10 female) were interviewed. When it was questioned about their attitude or willingness to include ESBD in ODL system of Education, the tutors shared their concerns of policy implementation, barriers, resources and behavioral mindset of normal students and their parents. But most of them were willing to include the ESBD students because of unique structure and nature of DOL system. Though attitude and willingness of the tutors was very much positive but they showed their concerns regarding handling of such students with large number of students attached with them. They were with view that in online or face to face tutorial meetings it will be difficult for them to address queries and issues with these students. One of the postgraduate level tutor said:

"I am afraid how I can handle or accommodate behavioural difficulties students with hearing, visual impaired and physically

handicapped students. Because I have no experience to include

them and meet their special needs. I need assistant tutor that I

can manage all these at a time with full dedication and

commitments". (Saleem, 2019)

Jamil with more than 15 years experience of ODL system and tutorship said:

"We are with full motivation to accommodate or include ESBD but understanding behavioural difficulties is much 
difficult for me because in MA Special Education program much of the discussion was on general disability and my specialization is with hearing impairment so I need special training to include ESBD”.

In conclusion of the discussion on theme 1 most of the tutors were with the point of view that they are lacking experience and knowledge to handle ESBD students but we are willing to include them in ODL system. AIOU may arrange training of one to two weeks on inclusion of ESBD.

\section{Theme 2 - Technical, Human, Financial, Moral and Professional Support}

Allama Iqbal Open University is the only public sector university providing free education to special need students at all level from Matriculation to $\mathrm{PhD}$ level. The university having potential and experience to accommodate disable students in mainstream ODL system of Education. As the university is providing free education so there is no financial issue and providing full financial support to students and their tutors. Department of Special Education is oldest and well known department train the teachers for special need children. Every year department enrolled more than 2000 prospective teachers of special education. Therefore technical assistance to special need students and their tutors is continuous practice of the department. Department also provide guidance and counseling services to the parents of special need students enrolled in AIOU. On the demand of tutors department made commitments to train the tutors for ESBD students. There are sufficient numbers of tutors available with qualification of special education and with experience to accommodate or include special need students in ODL system of education. Most of the tutors' suggested assistant tutor as support staff by this tutor will be able to accommodate ESBD with any disturbance. There will be no disturbance in online discussion, chat, blogs and online lectures. Following conclusions drawn by the researcher on theme two:

Mahreen a postgraduate tutor said while talking the support she received:

"AIOU provided full support for inclusion of special need students and I have professional qualification in special education but I still felt lack of knowledge to understand the concept of behavior difficulties and how I can make adaptations in teaching and academic guidance as a tutor. I also found it 
difficult to guide my other students to behave and communicate with ESBD".

In conclusion of theme two researchers found that most of the tutors felt they are lacking in knowledge and understanding the behavioral difficulties and how to handle them in online or face to face tutorial meetings and face to face lectures during workshops. In discussion it was found that tutors are feared that how they can deal ESBD on one-o-one basis which they already faced in inclusion of hearing, visual impaired and physically disabled students. They also shared the issue of training and guidance to normal students that how they behave with their class fellows with ESBD.

\section{Theme 3 - Suggestions/Recommendations for the implementation of Inclusion Policy in ODL}

In interviews tutors were asked regarding question three i.e. suggestions and recommendations for the implementation of inclusion policy in AIOU. Here they suggested many positive and valuable points for AIOU. One of the important suggestion as discussed in theme two assistant to tutor to accommodate special need students with normal students. The response guided me as researcher to make recommendations that AIOU must develop a conducive and consistent environment for all the special need or disable students that they can fee inclusive environment without any discrimination. They elaborated the conducive inclusive environment that they need more physical support, more financial and human resources and training for the staff and normal students enrolled in the same program with ESBD.

Most of them articulated that AIOU must ensure the more conducive teaching-learning environment. Also they suggested training of other tutors on inclusion of ESBD and other special need students. They emphasized that training for the tutors already having special education should be practice of AIOU. Suggestions also included training of normal students and their parents that they can understand the concept of inclusion and clear their negative myth behind inclusion. Finally they suggested training of tutors for behavior management strategies/ techniques to accommodate ESBD and they can make adaptations in teaching strategies and evaluation process.

The tutors also suggested training of eLearning staff, eLearning Instructional Designer and staff involved in administrative matters. The etutors frequently expressed that they felt steadiness, continuous help and sufficient time to execute the implementation approaches which increase skill to accommodate or teach ESBD. 
"Shahnawaz believed that if AIOU provide the opportunity for the tutors to get and update their knowledge, he/she can convince the other stakeholders for positive attitudes and have their willingness for inclusion of ESBD".

By this stakeholders will be more motivated and encouraged for more successful inclusive learning environment at AIOU. Also by this teachers can manage the negative behavior of normal students in inclusive classroom (ODL tutorial meetings and workshop lectures). They also expressed that professional support should address individual differences of children and tutors should consider their special needs in online and offline guidance. Training also address support for parents and parents involvement in inclusive education. Parents felt by this training they are part of inclusive classroom and by this teachers are more confident to accommodate special needs of ESBD students.

If we conclude or summarize the qualitative data we conclude that tutors though have professional qualification i.e. special education but they are lacking to understand the best behavior management techniques and approaches to handle the unwanted behavior of students presented in inclusive classroom. This also linked with less or no human/staff support which creates more problems in inclusive classroom. They expressed that in Pakistan we mostly have limited financial resources so assistant tutor or more staff will be a big milestone for AIOU. If they are without support staff they will in stress, overburden and not able to promote inclusion successfully. Also they shared that tutor's confidence and level of communication with staff and parents linked with extra staff, support from other tutors, resources and trainings.

\section{Discussion}

The study is unique in natures that there is no public or private sector university accommodating special need students at higher education. The main aims or objectives of the study were to determine the attitudes of Open and Distance Learning tutors or instructors to include the special need students especially emotional, social and behavioral difficulties students. Also to explore the level of technical, human, moral, financial and professional support they received from AIOU. Third and last objective was to check the relation with tutors' attitude of inclusion and their enthusiasm to teach students with ESBD. Research also aimed to check the difficulties to include the ESBD students.

Researcher summarized the main findings, technical and professional experience was the significant predictor of ODL tutors' attitudes to 
include students with ESBD. Tutors with less experience found more positive to include students with emotional, social and behavioral difficulties as compared to more experienced tutors found less positive in terms of attitude of inclusion. Tutors with professional qualification of MA/MEd Special Education and tutors with professional and academic qualifications both were with positive attitude and willingness to include ESBD in ODL system of Education. It was found that tutors received support were more positive for inclusion, also significantly correlated with amount of support received and positive attitude and willingness. Both willingness and attitudes scales showed moderate to strong correlations. Professional and academic qualifications correlated with attitudes and willingness and with some other variables. An important finding or result was that attitudes significantly predicted willingness to accommodate students with social, emotional and behavioral difficulties in ODL system, regardless of the amount of support they received. The analysis of qualitative data also verified the findings of quantitative data i.e. positive correlation between attitudes and willingness with professional and academic qualifications but negative or moderate with experience. Tutors reported in interviews that the amount of support they received from AIOU is sufficient but they need training in ESBD.

Research question on types of support received by the tutors explored that tutors were satisfied with the technical, academic, moral, human and financial support they received from AIOU. The finding is in line with the Hwang, \& Evans (2011) findings that greater the support received by the tutors the more efficiency and comfort the tutor to handle the special needs of ESBD in ODL system. Tutors' responses also confirmed that lacks of resources are among major barriers of ESBD inclusion. Moberg \& Savolainen (2003) found that teachers trying to include ESBD with limited resources and support felt these should be in special schools not in mainstream. Financial resources or funding to include ESBD or other special need students in formal or ODL system found another major barrier which restricts inclusion or implementation of inclusion policies at school level and at higher education. In interviews tutors shared that at the beginning of the project limited financial assistance/incentives lower the tutors' enthusiasm and spirit which was not at the end of the project, in result all the ESBD sustained in the ODL system. Tutors also reported that they were incapable to fulfill their task because some of the variables were not in their control, 
training and follow-up support rescued them in the situation. On followup and sufficient support received from AIOU made the inclusion process more sustainable and consistent. Variables of age, experience and qualification of tutor in ODL system also correlated with the attitudes and willingness of the tutors towards inclusion of ESBD. It is more in tune with researches conducted previously especially Monsen, Ewing, \& Kwoka, M. (2014) research. Current research finding fresh tutors are less willing as compare to experience was contradicted with the Yan and Sin (2014) findings. Response in qualitative information reported that fresh or less experienced were with concerns of capacity and skills to accommodate or handle the problems of ESBD in mainstream classroom. Most of them were with view that they need more training and experience to include them. In nut shell experienced tutors were more confident to include the ESBD as compare to less experience. Goodman and Burton (2010) findings were in line with the findings or current study that tutors get all types of support promotes inclusion successfully in mainstream and ODL system of education. Qualitative information of support the tutors received was not in line with the findings of Goodman and Burton (2010). In conclusion researcher found inclusion of ESBD in ODL system easier as compare to formal system of education. Tutors with institutional support, assistant tutor and resources accommodated ESBD with other special need students of ODL system. 


\section{References}

Armstrong, D. (2013). Educator perceptions of children who present with social, emotional and behavioural difficulties: A literature review with implications for recent educational policy in England and internationally. International Journal of Inclusive Education, 18(7), 731-745. doi:10.1080/13603116.2013.823245

Avramidis, E., Bayliss, P., \& Burden, R. (2000). A survey into mainstream teachers' attitudes towards the inclusion of children with special educational needs in the ordinary school one local education authority. Educational Psychology, 20(2), 191-211.10.1080/ 713663717

Broomhead, K. E. (2013). Preferential treatment or unwanted in mainstream schools? The perceptions of parents and teachers with regards to pupils with special educational needs and challenging behaviour. Support for Learning, 28(1), 4-10.10.1111/ sufl.2013.28.

Cole, T., \& Visser, J. (2005). Review of literature on SEBD definitions and 'good practice' accompanying the managing challenging behaviour report published by Ofsted (2005). Retrieved from http://www.ofsted.gov.uk

Cook, B. G., Cameron, D. L., \& Tankersley, M. (2007). Inclusive teachers' attitudinal ratings of their students with disabilities. The Journal of Special Education, 40(4), 230-238.10.1177/002246690 70400040401

Evans, J., Harden, A., \& Thomas, J. (2004). What are effective strategies to support pupils with emotional and behavioural difficulties (EBD) in mainstream primary schools? Findings from a systematic review of research. Journal of Research in Special Educational Needs, 4(1), 2-16.10.1111/J.1471-3802.2004.00015.x

Foorline, C., Keene, M., \& Barrett, E. (2008). The concerns of mainstream teachers: Coping with inclusivity in an Australian context. International Journal of Disability, Development and Education, 55, 251-264.10.1080/10349120802268396

Gerber, M. M. (1988). Tolerance and technology of instruction: Implications for special education reform. Exceptional Children, 54, 309314.10.1177/001440298805400404 
Glazzard, J. (2011). Perceptions of the barriers to effective inclusion in one primary school: Voices of teachers and teaching assistants. Support for Learning, 26(2), 56-63.10.1111/sufl.2011.26. issue-2

Goodman, RL. and Burton, DM. (2010). 'The inclusion of students with BESD in mainstream schools: teachers' experiences of and recommendations for creating a successful inclusive environment'. Emotional and Behavioural Difficulties. 15(3). 223-237.

Government of Pakistan (1981) "Disabled Persons' (Employment and Rehabilitation) Ordinance, 1981". URL Access: https://www.ilo.org/dyn/natlex/docs/ELECTRONIC/50075/97325/F 1697756412/PAK50075.pdf dated August 11, 2018.

Hager, P., \& Hodkinson, P. (2009). Moving beyond the metaphor of transfer of learning. British Educational Research Journal, 35(4), 619638.10.1080/01411920802642371

Hameed, A. (2014) "Situation of Disabled in Pakistan". Pakistan Association for Continuing and Adult Education: Lahore.

Hastings, R. P., \& Oakford, S. (2003). Student teachers' attitudes towards the inclusion of children with special needs. Educational Psychology, 23(1), 87-94.10.1080/01443410303223

Humphrey, N., \& Symes, W. (2010). Perceptions of social support and experience of bullying among pupils with autistic spectrum disorders in mainstream secondary schools. European Journal of Special Needs Education, 25(1), 77-91.10.1080/08856250903450855

Hwang, Y., \& Evans, D. (2011). Attitudes towards inclusion: Gaps between belief and practice. International Journal of Special Education, 26(1), 136-146.

Jordan, A., Schwartz, E., \& McGhie-Richmond, D. (2009). Preparing teachers for inclusive classrooms. Teaching and Teacher Education, 25, 535-542.10.1016/j.tate.2009.02.010

MacFarlane, K., \& Woolfson, L. M. (2013). Teacher attitudes and behavior toward the inclusion of children with social, emotional and behavioral difficulties in mainstream schools: An application of the theory of planned behavior. Teaching and Teacher Education, 29, 4652.10.1016/j.tate.2012.08.006 
MacFarlane, K., \& Woolfson, L. M. (2013). Teacher attitudes and behavior toward the inclusion of children with social, emotional and behavioral difficulties in mainstream schools: An application of the theory of planned behavior. Teaching and Teacher Education, 29, 4652.10.1016/j.tate.2012.08.006

McGregor, E., \& Campbell, E. (2001). The attitudes of teachers in Scotland to the integration of children with autism into mainstream schools. Autism, 5(2), 189-207.

Monsen, J. J., Ewing, D. L., \& Kwoka, M. (2014). Teachers' attitudes towards inclusion, perceived adequacy of support and classroom learning environment. Learning Environment Research, 17, 113126.10.1007/s10984-013-9144-8

Rakap, S., \& Kaczmarek, L. (2010). Teachers' attitudes towards inclusion in Turkey. European Journal of Special Needs Education, 25(1), 59$75.10 .1080 / 08856250903450848$

Ryan, T. G. (2009). Inclusive attitudes: A pre-service analysis. Journal of Research in Special Educational Needs, 9, 180-187.10.1111/ jrse.2009.9.issue-3

Scanlon, G., \& Barnes-Holmes, Y. (2013). Changing attitudes: Supporting teachers in effectively including students with emotional and behavioural difficulties in mainstream education. Emotional and Behavioural Difficulties, 18(4), 374-395.10.1080/ 13632752.2013. 769710

Yan, Z., \& Sin, K. (2014). Inclusive education: Teachers' intentions and behaviour analysed from the viewpoint of the theory of planned behaviour. International Journal of Inclusive Education, 18(1), 7285.10.1080/13603116.2012.757811

\section{Citation of this Article:}

Majeed, Z. (2020). Assessing ODL teachers/tutors' opinion inclusion of children with emotional, social behavioural difficulties in ODL. Pakistan Journal of Education, 37 (1), 01-20. 